\title{
Meta-analysis
}

\section{Difference in clinical profile between juvenile onset and adult-onset systemic lupus erythematosus: a meta-analysis}

\author{
Mandar Kalpesh Shah ${ }^{1 *}$, Mihika Ashish Shah ${ }^{1}$, Gayatri Anand Goghawala ${ }^{1}$, \\ Priyangi Manohar Kathayat ${ }^{1}$, Parshwa Keyur Shah ${ }^{2}$, Sharan Dharmesh Shah ${ }^{3}$, \\ Harshil Devang Patel ${ }^{4}$, Kaushal Patel ${ }^{5}$, Kiran Abbas ${ }^{6}$, Puja Srivastava ${ }^{7}$, Sapan C. Pandya ${ }^{7}$
}

\author{
${ }^{1}$ Smt. NHL Municipal Medical College, Ahmedabad, Gujarat, India \\ ${ }^{2}$ School of Engineering and Applied Science, Ahmedabad University, Ahmedabad, Gujarat, India \\ ${ }^{3}$ A. M. C Dental College and Hospital, Ahmedabad, Gujarat, India \\ ${ }^{4}$ G. C. S Medical College, Ahmedabad, Gujarat, India \\ ${ }^{5}$ Government Medical College, Surat, Gujarat, India \\ ${ }^{6}$ Jinnah Postgraduate Medical Centre, Karachi, Pakistan \\ ${ }^{7}$ VS Hospital, Ahmedabad, Gujarat, India
}

Received: 11 September 2021

Revised: 10 November 2021

Accepted: 23 November 2021

\section{*Correspondence:}

Dr. Mandar Kalpesh Shah,

E-mail: shahmandar20@gmail.com

Copyright: (C) the author(s), publisher and licensee Medip Academy. This is an open-access article distributed under the terms of the Creative Commons Attribution Non-Commercial License, which permits unrestricted non-commercial use, distribution, and reproduction in any medium, provided the original work is properly cited.

\begin{abstract}
The aim was to systematically review the studies that compared clinical and serological variation between adult-onset systematic lupus erythematosus (aSLE) andjuvenile-onset systematic lupus erythematosus (jSLE). A comprehensive literature search was done, in various available electronic databases for relevant publication that compared juvenile onset SLE and adult onset SLE. The data of adverse clinical features, serological profile and mortality were extracted. Juvenile onset was defined as $\leq 18$ years and adult onset was defined as $>18$ years. The methodological quality of study was assessed by Newcastle Ottawa scale (NOS) criteria and R version 3.3.1 was used for analysis and ORs and 95\% CIs, were used as statistical parameter. A total of 14,920 patients; (12,230: aSLE, and 2,690: jSLE) were included. Renal involvement especially nephritis was significantly more in j-SLE OR: $2.18,95 \%$ CI: [1.81;2.62]; $\mathrm{I} 2=10.8 \%$ whereas musculoskeletal was significant in aSLE O.R: 0.64; C.I: $[0.44 ; 0.93] ; \mathrm{I} 2=83.4 \%$. Seizure and malar rash were significantly higher in J-SLE OR:1.69, CI: [1.31; 2.18]; I2=31.1\%,1.43; C.I [1.04; 1.97]; I2=82\%, respectively. Raynaud's phenomenon and pleuritis were significantly higher in adult onset SLE. Anemia and thrombocytopenia were significantly higher in juvenile onset SLE. Anti-ds DNA, anti-histone, and anti-ribosomal-P were more frequent in juvenile-onset SLE while, anti-Ro was more common in adult-onset disease. The cause of mortality was not significantly different in both groups. Renal biopsy of class III and IV combined and class V were significantly more in adult-onset SLE. SLEDAI was higher in j-SLE. Meta-analysis indicated that, regardless of many similar clinical and serological manifestations, there is still some variation between adult-onset SLE and juvenileonset SLE. Although, SLE disease is continuum from juvenile to adult but disease aggressive in juvenile onset SLE.
\end{abstract}

Keywords: Auto antibodies, Juvenile, Nephritis, Systemic lupus erythematosus, Adult onset

\section{INTRODUCTION}

The systemic lupus erythematosus (SLE) is the prototype multisystem autoimmune disease with a relapsing and remitting disease course. It is characterized by presence of auto-antibodies that target healthy organs of the body. ${ }^{1}$ Symptoms vary from mild butterfly or malar rash to a severe nephritic or neuropsychiatric syndrome. ${ }^{2}$ 
The disease presentation is variable in different age groups and ethnic populations. SLE is more prevalent and aggressive in Asians and Hispanics as compared to Caucasians.

Also, disease tends to be more aggressive at juvenile onset SLE (jSLE); with higher prevalence of nephritis, seizures and neuropsychiatric involvement in jSLE, as compared to adult onset SLE (aSLE). Other manifestations like pleuritis and Raynaud's phenomenon are more common in a SLE. ${ }^{3}$

In this meta-analysis, we review the differences between juvenile and adult onset SLE, from all the published data between January 1980 till December 2019. For the purpose of comparison, we have chosen age at onset $<18$ years to be classified as juvenile onset SLE (jSLE) and $>18$ years to be classified as adult onset SLE (aSLE), according to most recent data. ${ }^{4}$

Most of the earlier studies are restricted to a certain population or region and have small sample sizes with cross-sectional study designs to recruit retrospective data. This may have underestimated the occurrence of both clinical and serological features. ${ }^{5-10}$ We used metaanalytical approach, involving a large number of patients from various regions, ethnicities, so that a more generalized form of data can be obtained.

The objective of the present meta-analysis study was to systematically review the studies that compared the clinical and serological variation and mortality outcome between aSLE and jSLE, to determine which clinical and serological features vary with the age of onset.

\section{METHODS}

\section{Data sources}

Dats sources used in the study were: Medline / PubMed database, EMBASE [Excerpta medica database], Scopus, google scholar, CINAHL [Cumulative index of nursing and allied health literature] database, Cochrane central register of controlled trials reference lists and official websites of several journals of rheumatology.

\section{Search strategies}

We used the following MesHtermsor keywords in different combinations and permutations for searching studies from year January 1980 to December 2019 in advanced PubMed search: "systemic lupus erythematosus", "age of onset", “adult-onset", "juvenile-onset", "paediatric-onset," “childhood-onset clinical", "serology", "antibodies". The abbreviation "SLE" was also used in this search process to replace its full-form. Only English publications were searched.

\section{Study selection}

We decided to include retrospective cohort or prospective cohort studies which have compared the clinical characteristics and serological profiles of juvenile onset SLE and adult onset SLE from January 1980 till December 2019.

The following data sources were searched: Medline/ PubMed database, EMBASE, Scopus, google scholar, CINAHL database, Cochrane central register of controlled trials reference lists and official websites of several journals of rheumatology.

\section{Inclusion and exclusion criteria}

Studies that satisfied the inclusion criteria were: The article must have compared the clinical and/or serological manifestations of adult-onset SLE with juvenile-onset SLE, had quantitative variables in the form of frequency or percentages, and were available in English language. Studies that reported their data in the form of dichotomous data (number of events), which could be used in this analysis. The disease activity at diagnosis was evaluated using the SLE disease activity index was also recorded for all studies which is a validated measure for disease activity for a-SLE and j-SLE. Lupus nephritis was defined by presence of the following criteria: persistent proteinuria $>0.5 \mathrm{~g}$ per day or greater than $3+$ by dipstick, and/or cellular casts including red cell, hemoglobin, granular, tubular or mixed). ${ }^{11}$

Studies were excluded based on the fact that: Abstracts were excluded if they had comparative data on a variable not listed above, or was specific to a small subset of patients, had incomplete or non- quantitative data.

Several studies presented data for three age groups: Juvenile-onset, adult-onset, and late-onset. Where possible, data for late-onset lupus was excluded and comparison was made between juvenile- onset and adultonset SLE.

If the same study population was used in more than one identified study, both studies were thoroughly assessed. If both reached the same conclusions, we dismissed the older study.

Duplicate studies or replicated studies were excluded.

Types of participants, outcomes, and definitions: The analysis included participants with juvenile-onset and adult-onset SLE, respectively. Juvenile-onset was defined as onset below 18 years of age and adult-onset after 18 years, but before 50 years.

Clinical manifestations included in the study for analysis were: general renal involvement; (from 15 studies), general cardiovascular involvement; (from 11 studies), general pulmonary involvement; (from 9 studies), general 
neurological and neuropsychiatric involvement; (from 10 and 9 studies), gastrointestinal involvement; (from 5 studies), musculoskeletal involvement; which included of arthritis and arthralgia (from 22 studies), hematological involvement;(from 5 studies) and dermatological involvement; (from 6 studies).

Additional detailed manifestations included in the study were: Renal involvement: nephritis; (from 8 studies), renal biopsy (class I, class II, class III, class IV, class V, class VI), renal biopsy class I and II and class III and IV were combined respectively for the analysis.

Neurological and neuropsychiatric involvement: Seizures (from 9 studies), psychosis (from 9 studies).

Hematological involvement: Leucopenia; (from 15 studies), lymphopenia; (from 11 studies), anemia (from 19 studied) and thrombocytopenia (from 21 studies).

Dermatological involvement: Malar rash; (from 21 studies), discoid rash; (from 16 studies), oral ulcers; (from 19 studies) and alopecia (from 8 studies).

Other clinical manifestations: Fever; (from 9 studies), photosensitivity; (from 20 studies), Raynaud's phenomenon; (from 8 studies), pleuritis; (from 8 studies) and pericarditis (from 7 studies).

Autoantibodies included in the study for analysis were: Anti-nuclear antibody (ANA); (from 20 studies), antidsDNA antibody; (from 21 studies), anti-cardiolipin antibody; (from 14 studies), anti-histone antibody; (form 2 studies), anti-Ro/SSA antibody; (from 12 studies), antiSm antibody; (from 17 studies), anti-La/SSB antibody; (from 13 studies), anti-RNP antibody; (from 10 studies), anti-ribosomal P antibody; (from 3 studies), lupus anticoagulant; (from 12 studies) and anti-phospholipid antibody (APLA); (from 5 studies).

Mortality outcomes included in the study for analysis were: Mortality due to infection; (from 8 studies), Mortality due to renal failure; (from 5 studies), mortality due to central nervous system involvement; (from 4 studies), mortality due to cardiovascular involvement; (from 4 studies) and SLE disease activity index (SLEDAI) was also included for the analysis; (from 8 studies).

\section{Data extraction}

We extracted information such as the year of study, sample size, location, and mean age at time of diagnosis for both adult-onset SLE and juvenile-onset SLE. Study quality was assessed by using the NOS, where each study was assessed on the basis of 8 items (Table 2).

\section{Data review}

We used a five-reviewer approach for selecting the studies for meta-analysis to minimize reviewer bias. Two reviewers separately searched for papers using the set inclusion and exclusion criteria as mentioned above. Once the first screening process was done, and repeated publications were removed, the same reviewers skimmed through the articles' abstracts, making sure all those studies met the eligibility criteria before finalizing them for full paper review. The next two reviewers studied the full papers, assessing them thoroughly for redundant findings, unnecessary variables, qualitative study designs, language barriers, etc., If there was disagreement, a fifth reviewer was requested to read the full paper and decide whether to include or exclude the paper.

\section{Data analysis}

The raw numerical data (event frequency) were extracted from the studies and analyzed using $\mathrm{R}$ version 3.3.1 ( $\mathrm{R}$ foundation for statistical computing). As a basic step, we carried out direct pair wise analysis by Mantel-Haenszel method. In the case of cohort studies, data were extracted from only a one-time point (most latest). The extracted data from all studies were combined for each clinical manifestation as well as serological profile variables using forest plots. We also combined several related clinical and serological manifestations into a single forest plot, demonstrating a general trend within the interrelated variables. The $\mathrm{Q}$ statistic or $\mathrm{I} 2$ index was used to measure the heterogeneity between the studies. I2 value of $0 \%$ to $24.9 \%, 25 \%$ to $49.9 \%, 50 \%$ to $74.9 \%$ and $75 \%$ to $100 \%$ were considered having no, mild, moderate and significant threshold for statistical heterogeneity. The random effects model (Hartung-Knapp adjustment) was used to calculate the pooled odds ratios (ORs) in case of heterogeneity greater than $50 \%$. Odds ratios (ORs) that crossed the point of no effect i.e., 1 indicated that the clinical or serological variable being studied was more frequent in patients with juvenile-onset SLE. If heterogeneity value was less than $50 \%$, we considered fixed effects. The presence of small-study effects or publication bias was assessed by a funnel plot.

\section{RESULTS}

The PRISMA study guidelines was used. ${ }^{34}$ At first 347 articles from PubMed /Medline, Embase and CINAHIL and other 216 were obtained through Scopus and google Scholar. Then 199 publications were removed as they were repeated. Further articles were eliminated basis of (Figure 1): The study which did not compare j-SLE with a-SLE, the study which did not have comparative data on variables of interest and the studies which were limited by language.

A total of 28 studies were included for the analysis from United States of America, India, Columbia, Portugal, Brazil, Iran, Belgium, Egypt, Korea, China, Taiwan, Oman, Turkey, Netherlands, Hungary, Thailand, Canada and USA (Table 1). . $^{5-10,12-32}$ 
Table 1: Characteristics of included studies, $(n=28)$.

\begin{tabular}{|c|c|c|c|c|c|c|}
\hline \multirow{2}{*}{ Study, years } & \multirow{2}{*}{ Country } & \multirow[t]{2}{*}{ Study design } & $\begin{array}{l}\text { Total no. } \\
\text { of } \\
\text { patients }\end{array}$ & $\begin{array}{l}\text { Total } \\
\text { no. of } \\
\text { patients }\end{array}$ & $\begin{array}{l}\text { Age at time } \\
\text { of diagnosis } \\
\text { mean } \pm \text { SD } \\
\text { (years) }\end{array}$ & $\begin{array}{l}\text { Age at time } \\
\text { of diagnosis } \\
\text { Mean } \pm \text { SD } \\
\text { (years) }\end{array}$ \\
\hline & & & $\begin{array}{l}\text { Juvenile- } \\
\text { onset } \\
\text { SLE }\end{array}$ & $\begin{array}{l}\text { Adult- } \\
\text { onset } \\
\text { SLE }\end{array}$ & $\begin{array}{l}\text { Juvenile- } \\
\text { onset SLE }\end{array}$ & $\begin{array}{l}\text { Adult- } \\
\text { onset SLE }\end{array}$ \\
\hline Esen et al, 2017 & Turkey & Cohort & 216 & 719 & $13.7 \pm 3.5$ & $34 \pm 11.3$ \\
\hline Fatemi et al, 2016 & Iran & Retrospective cohort & 138 & 352 & $14.5 \pm 3$ & $30 \pm 10$ \\
\hline Nabi et al, 2018 & Egypt & Retrospective cohort & 83 & 215 & $12.63 \pm 3.1$ & $29.65 \pm 10.2$ \\
\hline Rasbi et al, 2018 & Oman & Cohort & 86 & 139 & $9.5 \pm 4.2$ & $28 \pm 9$ \\
\hline Mok et al, 2005 & China & Prospective study & 50 & 213 & $12.9 \pm 2.4$ & $31.1 \pm 9.1$ \\
\hline Mohamed et al, 2017 & Egypt & Cohort & 80 & 80 & $12.8 \pm 2.1$ & $29.9 \pm 7.2$ \\
\hline Brunner et al, 2008 & Canada & Cohort & 67 & 131 & $12.7 \pm 2.5$ & $36.0 \pm 13.2$ \\
\hline Hoffman et al, 2008 & Belgium & Cohort & 56 & 193 & 15 & 32 \\
\hline Pande et al, 1993 & India & Cohort & 83 & 187 & - & - \\
\hline Feng et al, 2010 & China & Observational & 108 & 1551 & $31 \pm 12$ & \\
\hline J.Choi et al, 2015 & Korea & Cohort & 27 & 149 & $14.2 \pm 2.1$ & $33.8 \pm 8.2$ \\
\hline Font et al, 1998 & Spain & Observational & 34 & 396 & $11(5-14)$ & $32(15-48)$ \\
\hline $\begin{array}{l}\text { Janwityanujit et al, } \\
1995\end{array}$ & Thailand & Observational & 51 & 308 & $11(3-14)$ & $28(25-49)$ \\
\hline Carreno et al, 1999 & Spain & Cohort & 49 & 130 & $13.04 \pm 3.50$ & $35.13 \pm 12.84$ \\
\hline Tucker et al, 2008 & $\begin{array}{l}\text { U.S. of } \\
\text { America }\end{array}$ & Cohort & 31 & 48 & $16.7 \pm 1.7$ & $32.3 \pm 9.2$ \\
\hline Medeiros et al, 2015 & Brazil & Cohort & 60 & 338 & $15.5 \pm 2.0$ & $29.8 \pm 8.1$ \\
\hline Rood et al, 1999 & Netherland & Cohort & 35 & 135 & 12.3 & 37.9 \\
\hline Mehdat et al, 2019 & Egypt & Cohort & 106 & 420 & $9.9 \pm 2.5$ & $25.3 \pm 7.9$ \\
\hline $\begin{array}{l}\text { Gormezano et al, } \\
2016\end{array}$ & Brazil & Retrospective cohort & 336 & 1830 & $11.5(2.4-17)$ & $27(20-69.6)$ \\
\hline Fonseca et al, 2016 & Portugal & $\begin{array}{l}\text { Cross sectional } \\
\text { analysis }\end{array}$ & 38 & 166 & $13.2 \pm 3.4$ & $34.2 \pm 12$ \\
\hline Gomez et al, 2008 & Columbia & Cohort & 230 & 984 & $\begin{array}{l}16.4(14.2- \\
17.8)\end{array}$ & $\begin{array}{l}30.8 \\
(24.3-39)\end{array}$ \\
\hline Sassi et al, 2016 & Brazil & $\begin{array}{l}\text { Cross sectional } \\
\text { analysis }\end{array}$ & 89 & 419 & $14.5 \pm 3.5$ & $32.3 \pm 8.6$ \\
\hline
\end{tabular}

Table 2: Study assessment using the Newcastle Ottawa scale.

\begin{tabular}{|lll|}
\hline Studies & Country & Stars allotted \\
\hline Fatemi et al, 2016 & Asia & $* * * * * * *$ \\
\hline Al Rasbi et al, 2018 & Oman & $* * * * * *$ \\
\hline Nabi et al, 2018 & Egypt & $* * * * * * *$ \\
\hline Artim-Esen et al, 2017 & Istanbul & $* * * * * * *$ \\
\hline Brunner et al, 2008 & Toronto & $* * * * * * *$ \\
\hline Carreno et al, 1999 & Spain & $* * * * * * * *$ \\
\hline Mok et al, 2005 & Asia & $* * * * *$ \\
\hline Choi et al, 2001 & Korea & $* * * * * * *$ \\
\hline Das Chagas Medeiros et al, 2015 & Brazil & $* * * * * * * *$ \\
\hline Feng et al, 2010 & China & $* * * * * * * *$ \\
\hline Feng et al, 2013 & China & $* * * * * * * *$ \\
\hline Font et al, 1998 & Spain & $* * * * * * *$ \\
\hline Hoffman et al, 2008 & Belgium & $* * * * * * *$ \\
\hline Janwityanujitet al, 1999 & Thailand & $* * * * * *$ \\
\hline Mohamed et al, 2017 & Egypt & $* * * * * * * *$ \\
\hline Mehdat et al, 2019 & Egypt & $* * * * * * * * *$ \\
\hline Gormezano et al, 2016 & Brazil & \\
\hline
\end{tabular}




\begin{tabular}{|lll|}
\hline Studies & Country & Stars allotted \\
\hline Pande et al, 1993 & India & $* * * * * *$ \\
\hline Ramirez Gomez et al, 2008 & Latin America & $* * * * * * *$ \\
\hline Fonseca et al, 2016 & Europe & $* * * * * *$ \\
\hline Rood et al, 1999 & Netherland & $* * * * * *$ \\
\hline Sassi et al, 2016 & Brazil & $* * * * * * *$ \\
\hline Sousa et al, 2016 & Portugal & $* * * * * *$ \\
\hline Tucker et al, 2008 & United States & $* * * * * * *$ \\
\hline Gheita et al, 2011 & Africa & $* * * * * *$ \\
\hline Tarr et al, 2014 & Africa & $* * * * * * * *$ \\
\hline Joo et al, 2016 & Asia & $* * * * * * * *$ \\
\hline Tu et al, 2011 & Asia & $* * * * * * *$ \\
\hline
\end{tabular}

Table 3: Difference in clinical manifestations between two groups.

\begin{tabular}{|c|c|c|c|c|c|}
\hline $\begin{array}{l}\text { System } \\
\text { involved }\end{array}$ & $\begin{array}{l}\text { Significant in } \\
\text { juvenile age group }\end{array}$ & $\begin{array}{l}\text { Significant in } \\
\text { adult age group }\end{array}$ & $\begin{array}{l}\text { Insignificant in both } \\
\text { the age groups }\end{array}$ & $\begin{array}{l}\text { Results, odds ratio } \\
{[95 \%, \mathrm{CI}]}\end{array}$ & $\mathbf{I}^{2}[\%]$ \\
\hline 1 & & & General dermatological & $1.01[0.55 ; 1.86]$ & 79.2 \\
\hline 2 & Malar rash & & & $1.43[1.04 ; 1.97]$ & 82.0 \\
\hline 3 & & & Discoid rash & $0.86[0.53 ; 1.39]$ & 54.2 \\
\hline 4 & Oral ulcer & & & $1.28[1.12 ; 1.46]$ & 44.8 \\
\hline 5 & & & Alopecia & $1.08[0.66 ; 1.78]$ & 57.0 \\
\hline 6 & & & $\begin{array}{l}\text { General hematological } \\
\text { involvement }\end{array}$ & $1.62[0.79 ; 3.30]$ & 79.0 \\
\hline 7 & & & Leucopenia & $1.59[0.99 ; 2.54]$ & 82.3 \\
\hline 8 & & & Lymphopenia & $1.28[0.83 ; 1.98]$ & 70.5 \\
\hline 9 & Anemia & & & $1.91[1.41 ; 2.59]$ & 77.5 \\
\hline 10 & Thrombo-cytopenia & & & $1.38[1.02 ; 1.85]$ & 57.9 \\
\hline 11 & & & $\begin{array}{l}\text { General cardiovascular } \\
\text { involvement }\end{array}$ & $1.15[0.91 ; 1.46]$ & 22.8 \\
\hline 12 & & & $\begin{array}{l}\text { General pulmonary } \\
\text { Involvement }\end{array}$ & $0.99[0.50 ; 1.94]$ & 68.4 \\
\hline 13 & & & $\begin{array}{l}\text { General neurological } \\
\text { Involvement }\end{array}$ & $1.77[0.95 ; 3.30]$ & 59.9 \\
\hline 14 & Seizures & & & $1.69[1.31 ; 2.18]$ & 31.1 \\
\hline 15 & & & Psychosis & $1.13[0.81 ; 1.56]$ & 0.0 \\
\hline
\end{tabular}

A total number of 14,920 (2,690 with juvenile-onset SLE and 12,230 with adult-onset of SLE) who were enrolled from the year 1980 to 2019 were included in the analysis. The total number of males were 4348 (29.1\%) with 760 $(25.9 \%)$ with juvenile-onset SLE and 3588 (29.4\%) with adult-onset SLE. The total number of females were $10,572(70.9 \%)$ with $1930(74.1 \%)$ females had juvenileonset SLE and $8642(70.6 \%)$ females with adult-onset SLE.

\section{Systemic involvement}

\section{Renal involvement}

General renal involvement especially nephritis was found to be significantly higher in juvenile-onset SLE with OR: 2.18 , 95\% CI: [1.81; 2.62]; I2=10.8\% renal biopsy of class III and IV combined and class V were significantly more in adult-onset SLE whereas class I and II combined and class VI were found in both the age groups with no significant difference (Table 3).

\section{Cardiovascular involvement}

Cardiovascular involvement and pericarditis was found in both the groups with no significant difference.

\section{Pulmonary involvement}

General pulmonary involvement was not significantly different in either age group but pleuritis was more common in adults.

Neurological involvement and neuropsychiatric involvement

General neurological involvement, general neuropsychiatric involvement and psychosis was not significantly different in either age group but the juvenile-onset SLE patients had more incidence of seizures compared with adult-onset SLE patients with OR: 1.69 , CI: $[1.31 ; 2.18] ; \mathrm{I} 2=31.1 \%$. 


\section{Gastrointestinal involvement}

General gastrointestinal involvement did not show any difference towards either age group.

\section{Musculoskeletal involvement}

General musculoskeletal manifestations including arthritis and arthralgia were more frequent in adult-onset SLE compared with juvenile-onset SLE with O.R:0.64; C.I: $[0.44 ; 0.93] ; \mathrm{I} 2=83.4 \%$.

\section{Hematological involvement}

General hematological involvement was not significantly different in either age group but anemia with O.R: 1.91; $95 \%$ CI $[1.41 ; 2.59] ; \mathrm{I} 2=77.5 \%$ and thrombocytopenia) with O.R:1.38; 95\% C.I [1.02; 1.85] was more common in jSLE; I2 $=57.9 \%$. Leucopenia and lymphopenia was not significant difference to either age group.

\section{Dermatological involvement}

General dermatological manifestation was not significantly different in either age group but malar rash with 1.43 ; C.I $[1.04 ; 1.97]$; I $=82 \%$, and oral ulcers with O.R: 1.28 ; C.I $[1.12 ; 1.46]$; I2 $=44.8 \%$ was found more significant in juvenile-onset SLE. Discoid and alopecia was found in both the groups with no significant difference.

\section{Other clinical manifestations}

Fever was more significant in juvenile-onset SLE whereas Raynaud's phenomenon was more significant in adult-onset SLE. Photosensitivity was not significant in both the age groups.

\section{Serological manifestations}

Anti-ds DNA with O.R:1.54; C.I [1.14; 2.08]; I2=75\%, anti-ribosomal $\mathrm{P}$ with O.R 1.98; C.I [1.17; 3.35]; $\mathrm{I} 2=0.0 \%$ and Anti-histone with O.R.:1.69[1.02;2.78]; I2 $=0 \%$ was significant in juvenile-onset SLE while, AntiRo/SSA was significantly more in adult-onset disease with O.R: 0.55; C.I [0.46; 0.65]; I2=2.5\%. ANA, anti$\mathrm{Sm}$, anti-Cardiolipin, anti-La/SSB, lupus anticoagulant, Anti-RNP, antiphospholipid antibodies were not significantly different in the two age groups (Table 4).

\section{Causes of mortality}

There was no significant difference in the number of deaths between two groups. Mortality due to infections, cardiovascular manifestations, central nervous system manifestations and renal failure were also taken into consideration but no significant difference was found between both the age groups (Table 5).

\section{Systemic Lupus Erythematosus Disease Activity Index (SLEDAI)}

When disease activity scores were observed, it was found that patients with juvenile-onset SLE had a higher score on SLEDAI with O.R 3.52; C.I [ $1.43 ; 5.60]$; I $2=88.5 \%$ (Table 3).

Table 4: Difference in serological manifestations between two groups.

\begin{tabular}{|c|c|c|c|c|c|}
\hline $\begin{array}{l}\text { System } \\
\text { involved }\end{array}$ & $\begin{array}{l}\text { Significant in } \\
\text { juvenile age group }\end{array}$ & $\begin{array}{l}\text { Significant in } \\
\text { adult age group }\end{array}$ & $\begin{array}{l}\text { Insignificant in both } \\
\text { the age groups }\end{array}$ & $\begin{array}{l}\text { Results, odds ratio, } \\
{[95 \%, \text { CI }]}\end{array}$ & $\mathbf{I}^{2}[\%]$ \\
\hline $\begin{array}{l}\text { Antibody } \\
1\end{array}$ & & & ANA & $0.96[0.73 ; 1.24]$ & 0.0 \\
\hline 2 & Anti-dsDNA & & & $1.54[1.14 ; 2.08]$ & 75 \\
\hline 3 & & & Anti-cardiolipin & $1.20[0.76 ; 1.89]$ & 80.7 \\
\hline 4 & Anti-histone & & & $1.69[1.02 ; 2.78]$ & 0.0 \\
\hline 5 & & Anti-Ro & & $0.55[0.46 ; 0.65]$ & 2.5 \\
\hline 6 & & & Anti Sm & $0.92[0.72 ; 1.17]$ & 52 \\
\hline 7 & & & Anti La & $0.72[0.46 ; 1.14]$ & 59.4 \\
\hline 8 & & & Anti RNP & $0.77[0.52 ; 1.14]$ & 53.4 \\
\hline 9 & Anti-ribosomal P & & & $1.98[1.17 ; 3.35]$ & 0.0 \\
\hline 10 & & & Lupus anticoagulant & $1.28[0.89 ; 1.83]$ & 51.8 \\
\hline 11 & & & Anti-phospholipid & $0.89[0.18 ; 4.3]$ & 93 \\
\hline
\end{tabular}

Table 5: Difference in causes of mortality.

\begin{tabular}{|lllll|}
$\begin{array}{l}\text { Significant in } \\
\text { juvenile onset }\end{array}$ & $\begin{array}{l}\text { Significant in adult } \\
\text { onset }\end{array}$ & $\begin{array}{l}\text { Insignificant between age } \\
\text { groups }\end{array}$ & $\begin{array}{l}\text { Odds ratio } \\
{[95 \%, C I]}\end{array}$ & $I^{2}[\%]$ \\
\hline- & - & Infections & $0.761[0.40,1.42]$ & 7 \\
\hline- & - & Renal failure & $1.403[0.73,2.69]$ & 19 \\
\hline- & CNS & $1.718[0.85,3.49]$ & 0 \\
\hline- & - & CVS & $1.129[0.07,18.41]$ & 61 \\
\hline
\end{tabular}



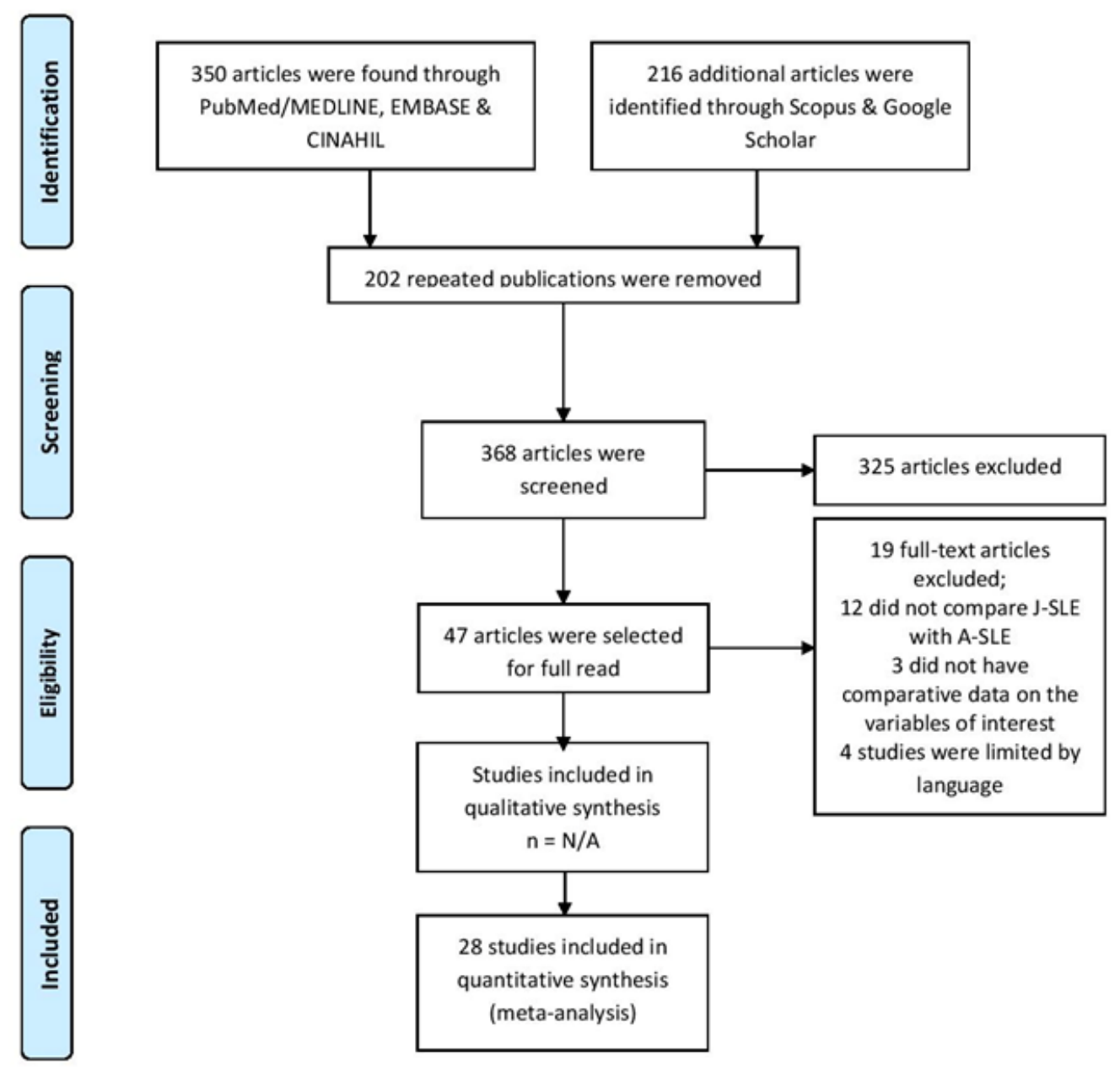

Figure 1: PRISMA.

Study

T. Tarr et al 2014

A. Fatemi et al 2016

M.Medeiros et al 2015

S.Sassi et al 2016

N.Gormezano et al 2016

I. Hoffman et al 2008

D.Mohamed et al 2017

Fixed effect model

Overall effect

Prediction interval

Heterogeneity: $I^{2}=15 \%[0 \% ; 59 \%], p=0.32$
Juvenile Adult
Events Total Events Total

$\begin{array}{rrrr}31 & 79 & 90 & 342 \\ 131 & 180 & 233 & 394 \\ 42 & 60 & 179 & 338 \\ 54 & 89 & 167 & 419 \\ 7 & 49 & 3 & 49 \\ 35 & 56 & 70 & 194 \\ 58 & 80 & 29 & 80\end{array}$

Figure 2: Forest plot of nephritis.
OR $\quad 95 \%-\mathrm{Cl} \begin{array}{r}\text { Weight } \\ \text { (fixed) }\end{array} \begin{array}{r}\text { Weight } \\ \text { (random) }\end{array}$

$1.808 \quad[1.084 ; 3.017] \quad 16.8 \% \quad 16.7 \%$

$1.847[1.257 ; 2.714] \quad 32.7 \% \quad 22.1 \%$ $2.073[1.147 ; 3.747] \quad 13.3 \% \quad 14.0 \%$ $2.328[1.458 ; 3.718] \quad 18.9 \%-18.4 \%$ $2.556[0.620 ; 10.527] \quad 2.1 \% \quad 3.5 \%$ $2.952[1.596 ; 5.462] \quad 9.7 \% \quad 13.4 \%$ $4.636[2.373 ; 9.059] \quad 6.5 \% \quad 11.9 \%$

$2.266[1.844 ; 2.785] 100.0 \% \quad \ldots$


[1.201; 4.580] 




Figure 3: Funnel plot of nephritis.

○ R.Fonseca et al 2016

$\triangle$ R.Gomez et al 2008

+ S.Sousa et al 2016

$\times$ S.Sassi et al 2016

$\diamond$ A.Fatemi et al 2016

$\nabla$ I.Hoffman et al 2008

$\otimes$ D.Mohamed et al 2017

* J.Choi et al 2015

$\oplus$ L.Carreno et al 1999

$\oplus$ C.Mok et al 2005

Y.Tu et al 2011

$\boxplus$ A.Rasbi et al 2018

\.Pande et al 1993

$\Delta$ M.Medeiros et al 2015

- N.Gormezano et al 2016

- T.Gheita et al 2011

$\Delta$ X.Feng et al 2013

- A.Esen et al 2017

- A.Nabi et al 2018

- M.Rood et al 1999

$\triangle$ Y.Joo et al 2016

+ H.Brunner et al 2008

$\times$ L.Tucker et al 2008

$\diamond$ T.Tarr et al 2014

$\nabla$ B.Medhat et al 2019

$\otimes$ J.Font et al 1998

* S.Janwityanujit et al 1995

$\diamond$ J.Feng et al 2010

Figure 4: Labels. 


\section{DISCUSSION}

In the present meta-analysis, disease characteristics and activity were compared between the adult-onset and juvenile-onset SLE patients from different corner of the world. Our meta-analysis is unique as it had not only analyzed the many diversified clinical and serological manifestations of SLE between adult-onset and juvenileonset SLE but also had taken into account the variation between the Renal Biopsy and the mortality outcomes in SLE.

We had found many similarities between adult-onset and juvenile-onset SLE; nevertheless, there were certain major dissimilarities between the two age groups. We found more frequent involvement of hematological, mucocutaneous, renal manifestations, seizures and certain autoantibodies with higher SLEDAI scores in j-SLE patients compared with a-SLE. In contrast, a-SLE patients had frequent involvement of the musculoskeletal system and pleuritis.

In our meta-analysis, we observed that renal involvement (nephritis) was more prevalent in juvenile-onset SLE patients compared to adult-onset SLE. This was in accordance with recent reviews by Mina et al and Papadimitraki et al who reported that lupus nephritis was associated with a higher mortality rate and poor prognosis. At some point of time during the disease, $60 \%$ of SLE patients develop have nephritis. ${ }^{34}$ Biopsy data was different probably because less number of children underwent renal biopsy. Our meta-analysis shows that, class 3 and class 4 which is focal and diffuse glomerulonephritis are more common in adult onset SLE as compared to juvenile onset SLE. There is no significant difference between juvenile onset SLE and adult onset SLE in class 1 (minimal mesangial hyperplasia) and class 2 (proliferative mesangial hyperplasia) whereas class 5 (Membranous nephritis) is significantly more observed in the adult onset SLE. Class 6 (sclerosing) shows no significant difference. The results are in accordance with Carreno et al and with the article of Nabi et al. ${ }^{13,15}$

Our findings were in contrast to a meta-analysis by Bundhun et al who observed that pulmonary involvement was significantly more prevalent in adult-onset SLE patients as compared to childhood- onset SLE whereas, in the present meta-analysis general pulmonary involvement did not vary significantly between the groups but specifically pleuritis was more common in adults. This finding was in accordance with meta-analysis by Livingston et al who reported that neither lung nor cardiac involvement was significantly different between the adult-onset SLE and childhood- onset SLE. ${ }^{35}$

Nevertheless, in contrast to Livingston et al we found that general hematological manifestations including anemia and leucopenia were more prominent in juvenile-onset.
Our meta-analysis shows that Malar rash and oral ulcers are significantly more involved in juvenile onset SLE; these results were not in accordance with the article of Bundhun et al which shows malar rash to be significantly involved in adult. ${ }^{36}$

Neurological involvement did not show significant difference but seizures were more common in juvenile onset SLE as compared to adult onset SLE which was consistent with article of Bundhun et al and Livingston et al. It was found that antibodies such as antiphospholipid antibodies and lupus anticoagulant increases the risk of seizures secondary to SLE ${ }^{36,37} \mathrm{~A}$ shorter time to seizure occurrence was seen in patients who had higher disease activity, renal involvement particularly WHO class IV glomerulonephritis and renal damage at baseline during the disease, may be this is the reason why seizure were more significant in juvenile onset SLE. ${ }^{38}$

As expected, we observed that in both groups i.e., adultonset SLE and juvenile-onset SLE, the majority of the patients were positive for autoantibodies (ANA), and no variation between the groups was observed. Nevertheless, our meta-analysis indicated certain variations in the serological profiles between the two age groups. For instance, anti-Ro/SSA was observed to be more prevalent in adult-onset SLE as compared to juvenile-onset SLE. Anti-dsDNA, Anti-histone, Anti-ribosomal antibodies were observed to be more prevalent in juvenile-onset SLE. However, anti-histone and anti- ribosomal antibodies comparison was from a limited number of studies and this limitation should be considered while construing these findings. Earlier published reviews by Papadimitraki et al reported that anti-dsDNA was more frequent in juvenile-onset SLE. ${ }^{2}$

There was no significant variation in between the two age groups for anti-La, anti-RNP, anti-Sm, anti- cardiolipin, lupus anticoagulant. These findings were somewhat in accordance with the meta-analysis by Livingston B. et al, who revealed no significant variation between adult-onset and childhood-onset SLE with respect to anti-Sm, antiRNP, and anti-La. ${ }^{35}$

Finally, upon comparing the disease activity scores at disease onset through the SLE disease activity index (SLEDAI), we reported that patients in the juvenile-onset SLE group had scored higher on the SLEDAI. This was in accordance with Livingston et al who also reported similar findings with respect to SLEDAI. ${ }^{35}$ Majority of the studies that were included in this meta-analysis that reported SLEDAI scores for both age groups collected the scores at the beginning of the study period. This helped eliminate any potential bias of adults having the disease longer than juvenile patients. However, it should be noted that our meta-analysis only observed one-point disease activity and can only assess the activity scores at the time of disease diagnosis. There was a lack of data on disease activity scores at different intervals in the disease course. 
The higher SLEDAI scores in j-onset patients were expected as in these patients there is an increased frequency of certain specific variables including lupus nephritis, neuropsychiatric, and dermatological manifestations which all contribute greatly to the SLEDAI scores.

The present analysis shows no significant difference in mortality between two groups. The major causes of the death in both groups are infection and renal failure (included nephritis). CNS and CVS are other etiology responsible for death.

Despite certain unavoidable limitations like the presence of heterogeneity among the studies which can pose as a limitation while construing the results of this metaanalysis, this meta-analysis has many strengthening points.

This is one the very few meta-analyses producing results from both clinical and serological point of view, comparing the data on autoantibodies, histopathological changes and survival outcome between adult-onset SLE patients and juvenile-onset SLE patients. The inclusion of studies from countries all around the world gives this review distinction over the previous ones. One of the main difficulties we faced while comparing data from published literature on adult- onset with juvenile-onset SLE was the fact that many juvenile-onset SLE patients are referred to adult health-care setups after they have reached a certain age limit. To deal with this confounding factor, we only included studies who enrolled participants in juvenile-onset SLE if they were 18 years or younger at the time of the study and excluded the j-onset SLE adult patients to minimize the bias among the age group.

Additional strong points include the selection of large sample size studies of at least more than 20 patients and generalizability of the results because of the inclusion of studies from many different countries. This meta-analysis provides a simple tool to physicians who have difficulty keeping abreast of a huge volume of medical literature especially in the field of rheumatology where the data is few and diverse among populations. This analysis has combined potential smaller data sets to display a complete picture of the disease in a simple form which provides statistical significance to evidence that may be previously absent.

\section{CONCLUSION}

This meta-analysis indicated that, regardless of the many similar clinical and serological manifestations, there are still some minor variations between adult-onset SLE and juvenile-onset SLE. More clear differences can study in prospective cohort studies.

\section{ACKNOWLEDGEMENTS}

Author would like to thank the rheumatology association of Gujarat, Gujarat chapter of the Indian rheumatology association (IRA). The rheumatology association of Gujarat constitutes of rheumatology experts who excel in their field, providing us with insight, guidelines and supreme supervision under which this paper was developed.

\section{Funding: No funding sources \\ Conflict of interest: None declared \\ Ethical approval: Not required}

\section{REFERENCES}

1. Meroni PL, Penatti AE. Epigenetics and systemic lupus erythematosus: unmet needs. Clin Rev Allergy Immunol. 2016,50:367-76.

2. Papadimitraki ED, Isenberg DA. Childhood-and adult-onset lupus: an update of similarities and differences. Expert Rev ClinImmunol. 2009,5:391403.

3. Barron KS, Silverman ED, Gonzales J, Reveille JD. Clinical, serologic, and immunogenetic studies in childhood-onset systemic lupus erythematosus. Arthritis Rheum. 1993;36:348-54.

4. Aggarwal A, Srivastava P. Childhood onset systemic lupus erythematosus: how is it different from adult SLE? Int j rheumatic dis. 2015;18(2):182-91.

5. Al Rasbi A, Abdalla E, Sultan R, Abdullah N, Al Kaabi J, Al-Zakwani I et al. Spectrum of systemic lupus erythematosus in Oman: from childhood to adulthood. Rheumatol Int. 2018,38:1691-8.

6. Artim-Esen B, Şahin S, Çene E. Comparison of disease characteristics, organ damage, and survival in patients with juvenile-onset and adult-onset systemic lupus erythematosus in a combined cohort from 2 tertiary centers in Turkey. J Rheumatol. 2017;44:619-25.

7. Ramírez Gómez LA, Uribe Uribe O, Osio Uribe O. Childhood systemic lupus erythematosus in Latin America. The GLADEL experience in 230 children. Lupus. 2008;17:596- 604.

8. Rood RT, Van Suijlekom-Smit L, Den Ouden E, Ouwerkerk F, Breedveld F, Huizinga T. Childhoodonset systemic lupus erythematosus: clinical presentation and prognosis in 31 patients. Scand $\mathbf{J}$ Rheumatol. 1999,28:222-6.

9. Sousa S, Gonçalves MJ, Inês LS. Clinical features and long-term outcomes of systemic lupus erythematosus: comparative data of childhood, adult and late-onset disease in a national register. Rheumatol Int. 2016,36:955-60.

10. Tucker LB, Uribe AG, Fernandez M. Adolescent onset of lupus results in more aggressive disease and worse outcomes: results of a nested matched casecontrol studywithin LUMINA, a multiethnic US cohort (LUMINA LVII). Lupus. 2008;17:314- 22.

11. Tan EM, Cohen AS, Fries JF, Masi AT, Mcshane 
DJ, Rothfield NF et al. The 1982 revised criteria for the classification of systemic lupus erythematosus. Arthritis Rheumatism. 1982;25(11):1271-7.

12. Fatemi A, Matinfar M, Smiley A. Childhood versus adult-onset systemic lupus erythematosus: long-term outcome and predictors of mortality. Clin Rheumatol. 2017;36:343-50.

13. Abdel-Nabi HH, Abdel-Noor RA. Comparison between disease onset patterns of Egyptian juvenile and adult systemic lupus erythematosus (single centre experience). Lupus. 2018;27(6):1039-44.

14. Carreno L, Lopez-Longo FJ, Monteagudo I. Immunological and clinical differences between juvenile and adult onset of systemic lupus erythematosus. Lupus.1999;8:287-92.

15. Brunner HI, Gladman DD, Ibañez D, Urowitz MD, Silverman ED. Difference in disease features between childhood-onset and adult-onset systemic lupus erythematosus. Arthritis Rheum. 2008;58:55662.

16. Mok CC, Mak A, Chu WP, To CH, Wong SN. Longterm survival of southern Chinese patients with systemic lupus erythematosus: a prospective study of all age-groups. Medicine. 2005,84:218-24.

17. Choi JH, Park DJ, Kang JH. Comparison of clinical and serological differences among juvenile-, adult-, and late-onset systemic lupus erythematosus in Korean patients. Lupus. 2015;24:1342-9.

18. Das Chagas Medeiros MM, Bezerra MC, Braga FH. Clinical and immunological aspects and outcome of a Brazilian cohort of 414 patients with systemic lupus erythematosus (SLE): comparison between childhood-onset, adult-onset, and late-onset SLE. Lupus. 2016;25:355-63.

19. Feng JB, Ni JD, Yao X, Pan HF, Li XP, Xu JH et al. Gender and age influence on clinical and laboratory features in Chinese patients with systemic lupus erythematosus: 1,790 cases. Rheumatology int. 2010;30(8):1017-23.

20. Feng X, Zou Y, Pan W. Associations of clinical features and prognosis with agent disease onset in patients with systemic lupus erythematosus. Lupus. 2014;23:327-34.

21. Font J, Cervera R, Espinosa G, Pallarés L, RamosCasals M, Jiménez $S$ et al. Systemic lupus erythematosus (SLE) in childhood: analysis of clinical and immunological findings in 34 patients and comparison with SLE characteristics in adults. Ann Rheumatic Dis. 1998;57(8):456-9.

22. Hoffman IE, Lauwerys BR, De Keyser F, Huizinga TW, Isenberg D, Cebecauer L et al. Juvenile-onset systemic lupus erythematosus: different clinical and serological pattern than adult-onset systemic lupus erythematosus. Ann rheumatic dis. 2009;68(3):4125.

23. Janwityanujit $\mathrm{S}$, Totemchokchyakarn $\mathrm{K}$, Verasertnlyom O, Vanlchapuntu M, Vatanasuk M. Age-related differences on clinical and immunological manifestations of SLE. Asian Pacific J allergy Immunol. 1995;13(2):145.
24. Mohamed DF, Aziz AB, Hassan SA, Shedid NH, ElOwaidy RH, Teama MA. Juvenile lupus: Different clinical and serological presentations compared to adult lupus in Egypt. Egyp Rheumatologist. 2018;40(1):55-8.

25. Medhat BM, Behiry ME, Sobhy N, Farag Y, Marzouk H, Mostafa N et al. Late-onset systemic lupus erythematosus: characteristics and outcome in comparison to juvenile-and adult-onset patients-a multicenter retrospective cohort. Clin Rheumatol. 2020;39(2):435-42.

26. Gormezano NW, Kern D, Pereira OL, Esteves GC, Sallum AM, Aikawa NE et al. Autoimmune hemolytic anemia in systemic lupus erythematosus at diagnosis: differences between pediatric and adult patients. Lupus. 2017;26(4):426-30.

27. Pande IR, Sekharan NG, Kailash S, Uppal SS, Singh RR, Kumar A et al. Analysis of clinical and laboratory profile in Indian childhood systemic lupus erythematosus and its comparison with SLE in adults. Lupus. 1993,2:83-7.

28. Fonseca R, Aguiar F, Rodrigues M, Brito I. Clinical phenotype and outcome in lupus according to age: a comparison between juvenile and adult onset. Reumatologiaclinica. 2018;14(3):160-3.

29. Sassi RH, Hendler JV, Piccoli GF, Gasparin AA, Da Silva Chakr RM, Brenol JC et al. Age of onset influences on clinical and laboratory profile of patients with systemic lupus erythematosus. Clin rheumatol. 2017;36(1):89-95.

30. Gheita TA, Fawzy SM, El-din AM, El-Fishawy HS. Juvenile and adult onset systemic lupus erythematosus outcome in Egyptian patients. Egyp Rheumatologist. 2011;33(2):99-105.

31. Tarr T, Dérfalvi B, Győri N, Szántó A, Siminszky Z, Malik A et al. Similarities and differences between pediatric and adult patients with systemic lupus erythematosus. Lupus. 2015;24(8):796-803.

32. Joo YB, Park SY, Won S, Bae SC. Differences in clinical features and mortality between childhoodonset and adult-onset systemic lupus erythematosus: a prospective single-center study. J Rheumatol. 2016,43:1490-7.

33. Tu YL, Yeh KW, Chen LC, Yao TC, Ou LS, Lee WI et al. Differences in disease features between childhood-onset and adult-onset systemic lupus erythematosus patients presenting with acute abdominal pain. Semin Arthritis Rheum. 2011;40:447-54.

34. Liberati A, Altman DG, Tetzlaff J, Mulrow C, Gøtzsche PC, Ioannidis JP et al. The PRISMA statement for reporting systematic reviews and metaanalyses of studies that evaluate health care interventions: explanation and elaboration. $\mathrm{J}$ clin epidemiol. 2009;62(10):e1-34.

35. Livingston B, Bonner A, Pope J. Differences in autoantibody profiles and disease activity and damage scores between childhood-and adult-onset systemic lupus erythematosus: a meta-analysis. Semin Arthritis Rheum. 2012;42:271-80. 
36. Bundhun PK, Kumari A, Huang F. Differences in clinical features observed between childhood-onset versus adult-onset systemic lupus erythematosus: A systematic review and meta-analysis. Medicine. 2017;96:37.

37. Gibbs Iii JW, Husain AM. Epilepsy associated with lupus anticoagulant. Seizure. 2002;11(3):207-9.

38. Andrade RM, Alarcon GS, Gonzalez LA, Fernandez M, Apte M, Vila LM et al. Seizures in patients with systemic lupus erythematosus: data from LUMINA, a multiethnic cohort (LUMINA LIV). Ann Rheumatic Dis. 2008;67(6):829-34.

Cite this article as: Shah MK, Shah MA,

Goghawala GA, Kathayat PM, Shah PK, Shah SD et al. Difference in clinical profile between juvenile onset and adult-onset systemic lupus erythematosus: a meta-analysis. Int J Res Med Sci 2021;9:3653-64. 